\title{
The Effects of siRNA SIRT1 on the Proliferation of Human Cervical Cancer Cells
}

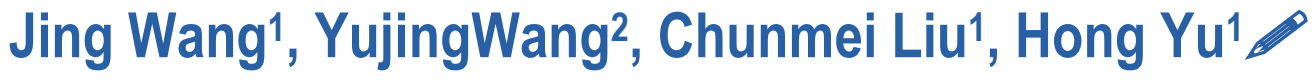

\author{
${ }^{1}$ Department of Medical Microbiology, Medical College, Qingdao University, Qingdao, 266071, China \\ ${ }^{2}$ Qilu Hospital of Shandong University Clinical Laboratory, Qingdao, 2660735, China
}

\begin{abstract}
To investigate the effects of small interfering RNA (siRNA ) SIRT1 on the proliferation of human cervical cancer cells with the hopes of finding new diagnostic and therapeutic modalities. Chemical synthesis of siRNA targeted against SIRT1 were transfected into human cervical cancer C33A cells by Lipofectmine RNAi-MAX liposomes, on harvesting at $72 \mathrm{~h}$ after transfection, the total RNA were extracted by the TRIZOL reagent and reverse transcribed into cDNA with the PrimeScript RT-PCR kit, and the expression level of SIRT1 mRNA was detected by RT-PCR. The cell proliferation was performed by CCK-8 method. RT-PCR results indicated that the mRNA expression of siRNA SIRT1 group was significantly down-regulated $(P<0.05)$ compared to the control groups. CCK-8 proliferation assay showed that the inhibition rate of siRNA SIRT1 group was $53.1 \%$, while the negative control group was $35.4 \%$, the inhibition rate of transfection reagent control group was $11.5 \%$. The inhibition rate of siRNA-SIRT1 group was significantly higher than other groups. Conclusion SIRT1 siRNA could down-regulate the expression of SIRT1 mRNA, inhibit the proliferation of C33A cells, suggesting that SIRTI has promoting abilities in human cervical cancer.
\end{abstract}

Keywords: SIRT1, RNAi, Cervical cancer cell

\begin{abstract}
Introduction
Cervical cancer is one of the most common cancer and the second leading cause of cancer-related death among women worldwide, with approximately 470,000 new cases and over 200,000 deaths per year ${ }^{[1-2]}$. Although chemotherapy and radiotherapy are still the major option for the treatment of invasive cervical cancer, its efficacy is limited because of high toxicity and drug resistance ${ }^{[1-2]}$. Therefore, it is necessary to develop more effective and less toxic anticancer agents.
\end{abstract}

SIRT1, a NAD(+)-dependent histone deacetylase, is known to play an important role in epigenetic silencing, suppressing recombination of rDNA, progression of the cell cycle, and longevity ${ }^{[3,4]}$. The role of SIRT1 in mammals is complex and less well characterized, however contradictory reports have suggested SIRT1 act as either tumor suppressing or promoting abilities, at present, little is known regarding the function of SIRT1 in human cervical cancer.

RNA interference (RNAi ) referred to a process characterized by sequence specific, post-transcriptional gene silencing(PTGS) directed by short interfering 21-23nt double-stranded RNAs. Several studies conducted in vivo and in vitro showed that RNAi application for targeting functional carcinogenic molecules, tumor resistance to chemotherapy and radiotherapy is required in today's cancer treatment ${ }^{[5-6]}$. Therefore, the present study was designed to investigate the effects of siRNA SIRT1 on the proliferation of human cervical cancer cells C33A. The purpose of this study was to use siRNA to characterize the effect of SIRT1 on the proliferation of human cervical cancer cells with the hopes of finding new diagnostic and therapeutic modalities.

\section{Materials and Methods}

Reagents

siRNA specific to (5'-ACUUUGCUGUAACCCUGUAdTdT-3') and the control siRNA were synthetized by Life technology Co., Lipofectamine RNAiMAX was pursased from Life technology Co., hGAPDH and SIRT1gene primers were synthetized by Life technology Co.. Cell Counting Kit-8 kit was from Wuhan boster biological engineering co., Ltd, China.

\section{Cell culture}

The human cervical cancer cells C33A were cultured in Dulbecco's Modified Eagle Medium (DMEM) supplemented with $10 \%$ fetal bovine serum. All cells were incubated at $37{ }^{\circ} \mathrm{C}$ in an incubator containing $5 \%$ $\mathrm{CO}_{2}$.

This article is published under the terms of the Creative Commons Attribution License 4.0 Author(s) retain the copyright of this article. Publication rights with Alkhaer Publications.

Published at: http://www.ijsciences.com/pub/issue/2016-03/

DOI: 10.18483/ijSci.986; Online ISSN: 2305-3925; Print ISSN: 2410-4477 


\section{siRNA Transfection}

siRNA SIRT1 and negative siRNA control were transfected by using Lipofectamine RNAi- MAX according to the manufacturer's instructions. Briefly, $\mathrm{C} 33 \mathrm{~A}$ cells $\left(3 \times 10^{4} /\right.$ well) were inoculated in the 24-well plate and incubated to reach30\%-50\%confluency $24 \mathrm{~h}$ after plating. Dilute $6 \mathrm{p}$ mol RNAi duplex in $100 \mu \mathrm{L}$ of DMEM in each well of the culture plate to be used for transfection. Mix the contents gently. Mix Lipofectamine RNAiMAX Rea gent gently before use. Add $1 \mu \mathrm{L}$ of Lipofectamine ${ }^{\circledR}$ RNAiMAX Reagent to each well containing the dilut ed RNAi molecules. Mix gently and incubate for 10$20 \mathrm{~min}$ at room temperature. Prepare $500 \mu \mathrm{L}$ of cells $\mathrm{f}$ or each transfection to be performed. Dilute trypsinize $\mathrm{d}$ adherent cells in complete growth medium so that 5 $00 \mu \mathrm{L}$ contains enough cells to reach $50-70 \%$ conflue ncy 24 after plating. Dilute suspension cells at a con centration of $40-100$ cells $/ \mu \mathrm{L}$. .Add $500 \mu \mathrm{L}$ of the dil uted cells to each well containing RNAi duplex- Lipofe ctamine ${ }^{\circledR}$ RNAiMAX Reagent. Mix gently by rocking the plate back and forth. The final RNA concentratio $\mathrm{n}$ is $10 \mathrm{nM}$ in a total volume of $600 \mu \mathrm{L}$. Incubate the cells $24-72$ hours at $37^{\circ} \mathrm{C}$ in a $\mathrm{CO}_{2}$ incubator until y ou are ready to assay for gene knockdown.

\section{Reverse transcription polymerase chain reaction (RT-PCR)}

On harvesting at $72 \mathrm{~h}$ after transfection, total RNA from C33A cells was extracted using the TRIZOL reagent (Invitrogen,Carlsbad, CA), according to the manufacturer's instructions. $1 \mu \mathrm{g}$ of total RNA (in triplicate) was reverse transcribed into cDNA using the PrimeScript RT-PCR kit (Takara Bio, Inc., Dalian, China). Subsequently, cDNA product was subjected to PCR amplification with TagDNA polymerase on a thermal cycle. The RCR conditions were as follows: preliminary degeneration at $94{ }^{\circ} \mathrm{C}$ for $1 \mathrm{~min}$, followed by 30 cycles of degeneration at $94{ }^{\circ} \mathrm{C}$ for $1 \mathrm{~min}$, annealing at $47{ }^{\circ} \mathrm{C}$ for $1 \mathrm{~min}$, extension at $72{ }^{\circ} \mathrm{C}$ for 1 min, extension at $72{ }^{\circ} \mathrm{C}$ for $10 \mathrm{~min}$ at last. The PCR products were loaded onto $1 \%$ agarose gels, scanning specific bandings by gel imaging system. The PCR primers used in this study are shown in Table I. Human GAPDH ( $h G A P D H)$ was used as the internal control.

Tab. 1 PCR primer sequence

\begin{tabular}{llc}
\hline Gene & \multicolumn{1}{c}{ Primer sequence } & \multicolumn{1}{c}{$\begin{array}{c}\text { PCR product length } \\
(\mathrm{bp})\end{array}$} \\
\hline hGAPDH & $\begin{array}{l}\text { Sense: 5'-GGCTCTCCAGAACATCAT-3' } \\
\text { Antisense: 5'-CACCTGGTGCTCAGTGTA-3' }\end{array}$ & 240 \\
SIRT1 & $\begin{array}{l}\text { Sense : 5'-TCAGTGTCATGGTTCCTTTGC-3' } \\
\text { Antisense: 5'-AATCTGCTCCTTTGCCACTCT-3' }\end{array}$ & 820 \\
\hline
\end{tabular}

\section{Proliferation assays}

Cell proliferation assays were performed using Cell Counting Kit- 8 kit. Logarithmic phase of C33A cells $\left(6 \times 10^{3} /\right.$ well $)$ were inoculated in the 96 -well plate and incubated for $24 \mathrm{~h}$, then Chemical synthesis of siRNA and transfection after a further incubation for $24 \mathrm{~h}, 48 \mathrm{~h}$ and $72 \mathrm{~h}, 10 \mu \mathrm{L}$ of CCK-8 solution was added into each well, followed by $2 \mathrm{~h}$ incubation at $37{ }^{\circ} \mathrm{C}$ in an incubator containing $5 \% \mathrm{CO}_{2}$, and then absorption value $A$ was measured in wavelength of $450 \mathrm{~nm}$ by a spectrophotometric plate reader (BioRad, Tokyo, Japan). All the experiments were carried out in triplicates. According to the formula: inhibition rate $=$ (control group A value-experimental group A value)/ control group A value $\times 100 \%$.

\section{Statistical analysis}

The experimental data are expressed as the Means \pm SD. The significance of the data was determined by one-way ANOVA analysis. The statistical significance of the differences between the values in each two groups was determined by q test. A P-value $<0.05$ was considered to indicate a statistically significance difference. All the statistical analysis were performed with SPSS13.0 software.

Results

Inhibition of siRNA SIRT1 on the expression of SIRT1

RT-PCR results showed that the mRNA expression of siRNA-SIRT1 group was significantly down-regulated $(P<0.05)$ compared to the control groups, while the negative siRNA control group and Lipofectamine ${ }^{\circledR}$ RNAiMAX Reagent group had no significant changes $(p>0.05)$. 


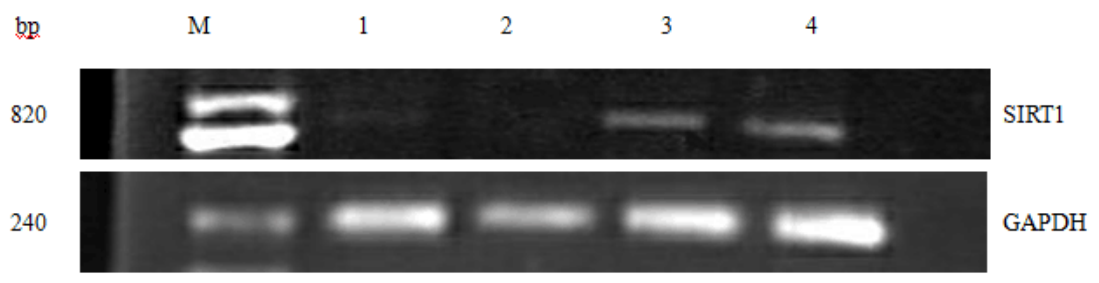

Fig1. Inhibition of SiRNA SIRT1 on the expression of SIRT1 mRNA 1.Sirt1-siRNA group, 2.negative siRNA control group

\section{Lipofectamine® RNAiMAX Reagent group 4. normal cell group}

Effect of SiRNA SIRT1on the proliferation of C33A cells

CCK-8 proliferation assay demenstrated that the inhibition rate of siRNA-SIRT1 group was 53.1\%, while the negative control group was $35.4 \%$, the inhibition rate of transfection reagent control group was $11.5 \%$. The inhibition rate of siRNA-SIRT1 group was significantly higher than other groups.

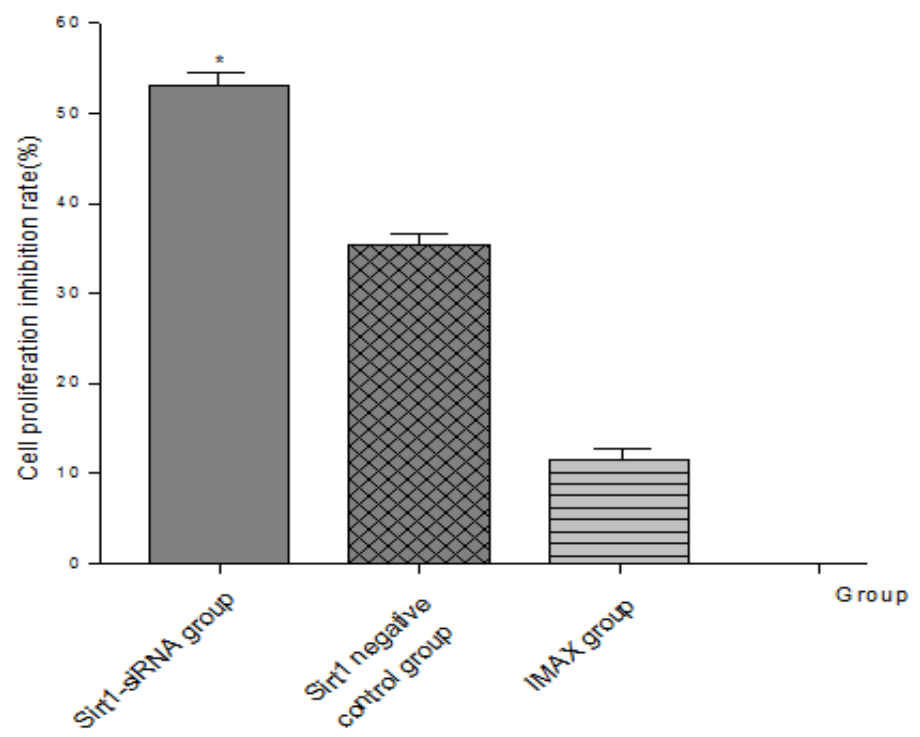

Fig2. Effect of siRNA SIRT1on the proliferation of C33A cells siRNA-SIRT1 group compared to the control groups and Lipofectamine ${ }^{\circledR}$ RNAiMAX Reagent group. * Refers to $P<0.05$

\section{Discussions}

SIRT1 contains at least two nuclear localization signals and two nuclear export signals, and can shuttle between the nucleus and cytoplasm under certain conditions ${ }^{[3,4]}$. It is believed that SIRT1 is involved in multiple tumors.SIRT1 expression is up-regulated in many types of cancers, such as breast cancer, lung cancer, ovarian epithelial tumours, hepatocellular carcinoma and prostate cancer et a ${ }^{[7-11]}$. SIRT1 enhances tumor angiogenesis through negatively modulating Delta-like ligand 4 (DLL4)/Notch signaling in Lewis lung carcinoma xenograft-derived vascular endothelial cells. SIRT1 also activates endothelial nitric oxide synthase by deacetylation to enhance nitric oxide production and improve vascular function. As a consequence, enhanced tumor angiogenesis induced by SIRT1 may bring more nutrition to cancer cells and facilitate their survival and growth. However, in some tumors, SIRT1 might be a tumor suppressor, and prolonged SIRT1 inhibition could have adverse effects. Several mouse studies demonstrated that over expression of SIRT1could reduce colon and intestinal polyps in APC $\mathrm{min} /+$ mice, thymic lymphoma in $\mathrm{p} 53^{+/-}$miceand spontaneous carcinoma/sarcoma, showing the tumor suppressor role of SIRT1 ${ }^{[12]}$.

SIRT1 may exert its antitumor functions by improving genome stability through enhancing DNA damage repair.

In this study, chemical synthesis of small interfering RNA (siRNA) targeting SIRT1 gene were transfected into cervical cancer $33 \mathrm{~A}$ cells to explore the effect of siRNA SIRT1 on the proliferation of human cervical cancer cells C33A. The results showed that SIRT1 siRNA could down-regulate the expression of SIRT1 
mRNA, inhibit the proliferation of C33A cells, suggesting that SIRT1 has promoting abilities in human cervical cancer. Therefore, treatment with siRNA targeted against SIRT1 might be a future treatment option against human cervical cancer.

\section{Referrences}

[1] Wright K O, Aiyedehin O, Akinyinka M R, et al. Cervical cancer: community perception and preventive practices in an urban neighborhood of lagos (Nigeria).[J]. ISRN Preventive Medicine, 2014, (2014): 9. doi: 10.1155/2014/950534.950534

[2] Berraho M, Obtel M, Bendahhou K, et al. Sociodemographic factors and delay in the diagnosis of cervical cancer in Morocco.[J]. Pan African Medical Journal, 2012, 12(1):14.

[3] Deng CX. SIRT1, is it a tumor promoter or tumor suppressor [J]. Int J Biol Sci.2009, 5(2):147-152.

[4] Li K, Luo J. The role of SIRT1 in tumorigenesis[J]. N Am J Med Sci.2011, 4(2): 104-106.
[5] Pauley KM, Cha S. RNAi therapeutics in autoimmune Disease[J]. Pharmaceuticals. 2013, 6(3): 287-294.

[6] Dykxhoorn D M, Judy L. Knocking down disease with siRNAs.[J]. Cell, 2006, 126(2):231-5.

[7] Lee H, Kim KR, Noh SJ, et al. Expression of DBC1 and SIRT1 is associated with poor prognosis for breast carcinoma[J]. Hum Pathol. 2011, 42(2): 204-213.

[8] Grbesa I, Pajares MJ, Martínez-Terroba E, et al. Expression of sirtuin 1 and 2 is associated with poor prognosis in non-small cell lung cancer patients[J]. PLoS One.2015, 10(4):e0124670.

[9] Jang KY, Kim KS, Hwang SH et al. Expression and prognostic significance of SIRT1 in ovarian epithelial tumours[J].Pathology. 2009, 41(4):366-371

[10] Chen J, Zhang B, Wong N, et al. Sirtuin 1 is unregulated in a subset of hepatocellular carcinomas where it is essential for telomere maintenance and tumor cell growth[J]. Cancer Res 2011, 71(12): 4138-4149

[11] Huffman DM, Grizzle WE, Bamman MM, et al. SIRT1 is significantly elevated in mouse and human prostate cancer[J]. Cancer Res. 2007, 67(14):6612-6618.

[12] Firestein R, Blander G, Michan S, et al. The SIRT1 deacetylase suppresses intestinal tumorigenesis and colon cancer growth[J]. Plos one, 2008, 3(4): e2020. 